\title{
A RARE CASE OF SEBACEOUS CYST IN RIGHT BREAST IN POSTMENOPAUSAL WOMAN
}

Abhinash Hazarika ${ }^{1}$, Geetha Avadhani², Nagesh $\mathrm{K}^{3}$

\section{HOW TO CITE THIS ARTICLE:}

Abhinash Hazarika, Geetha Avadhani, Nagesh K. "A Rare Case of Sebaceous CYST in Right Breast in Postmenopausal Woman". Journal of Evolution of Medical and Dental Sciences 2014; Vol. 3, Issue 27, July 07; Page: 7644-7647, DOI: $10.14260 /$ jemds/2014/2949

ABSTRACT: A sebaceous cyst is very rarely seen in breast, arising from sebaceous glands and having predilection towards inframammary fold. Malignant transformation has been reported. OBJECTIVE: To know the risk and complications of it. MATERIALS AND METHOD: A postmenopausal woman with sebaceous cyst in right breast who underwent excision in AIMS, B.G.Nagara is included. RESULT: Sebaceous cyst of breast is a benign condition associated with fewer complications. CONCLUSION: Surgical excision is the only treatment.

KEYWORDS: epidermal cyst, epidermal inclusion cyst.

INTRODUCTION: A breast sebaceous cyst, also sometimes known as an epidermal inclusion cyst, caused by blockage of sebaceous glands. Sebaceous glands secrete sebum which lubricates skin and hair. Sebaceous glands are in many areas of the body but most abundant in face and scalp.

Breast sebaceous cyst is a type of epidermal cyst which forms as a collection of keratin like material most common on face, back and scalp but also occurs on the breast. ${ }^{1}$ Breast sebaceous cyst often appears as a small bumps or lumps just beneath the skin as a small closed sac that contain the keratin which is foul smelling 'pasty' built up of protein.

A female patient aged about 63 yrs. who attained menopause 15 yrs. back, presented to surgical OPD with h/o lump in the upper quadrant of right breast since 8 years and foul smelling pultaceous discharge from lump since 3 days. There was no h/o trauma or fever and not a known case of DM.

A swelling measuring $10 \times 9 \mathrm{~cm}$ in right upper outer quadrant of right breast, skin over the lump was red and indurated, nipple areolar complex inverted, lump soft in consistency, fluctuant, non-tender, and moulds on pressure. A keratinous pultaceous foul smelling discharge from lump was present. Pectoral group, central axillary group of lymph nodes on right side palpable vitals were with in normal limit

Investigation: $\mathrm{Hb} \%-12 \mathrm{mg}$

Blood group: A positive

LFT/RFT: WNL

CXR: NRA

USG of Right Breast: Hypoechoic lesion measuring 10/10 cm at right upper outer quadrant. 


\section{CASE REPORT}

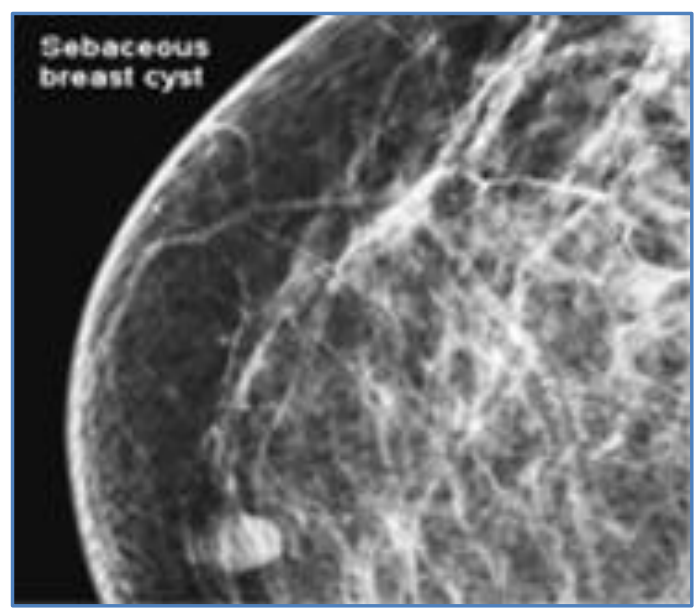

Mammographic Findings

FNAC: Macroscopy - foul smelling grey brown dirty pultaceous material.

Microscopy: Keratinous debritic material along with a nucleate squamous s/o Keratinous cyst.

Patient was posted for excision biopsy under GA. An elliptical incision including punctum over the right breast was taken, cyst wall separated from surrounding tissue, the entire cyst with capsule has been removed, which contains foul smelling pultacious materials and sent for HPE. Wound was approximated in layer and compression dressing done. Post-operative period was unremarkable. Sutures removed on $8^{\text {th }}$ post-op day.

HPE report shows, cyst lined by stratified squamous epithelium with thickened fibro collagenous wall. Many proliferated blood vessels and congested large blood vessels and focal collection of chronic inflammatory cells inclusive of plasma cells and few epithelioid cells suggestive of epidermal cyst with chronic inflammatory reaction.

DISCUSSION: A sebaceous cyst originates in the sebaceous gland while an epidermoid cyst, which is used interchangeably with the previous term, has its origin in the follicular infundibulum. These lesions are typically located in the skin or subcutaneous tissue. ${ }^{2}$ Most common site of sebaceous cyst face, scalp and scrotum but very rare in breast. There may be a predilection towards the inframammary fold. Mammographically usually seen as a well circumscribed as rounded soft tissue density lesion close to skin surface. Sonographically seen as a small hypoechoic located closely to the skin surface with through transmission and with no detectable vascular flow. Hypo and hyperechoic alternating rings may sometimes be seen. Doppler imaging may show quite remarkable flow. 


\section{CASE REPORT}

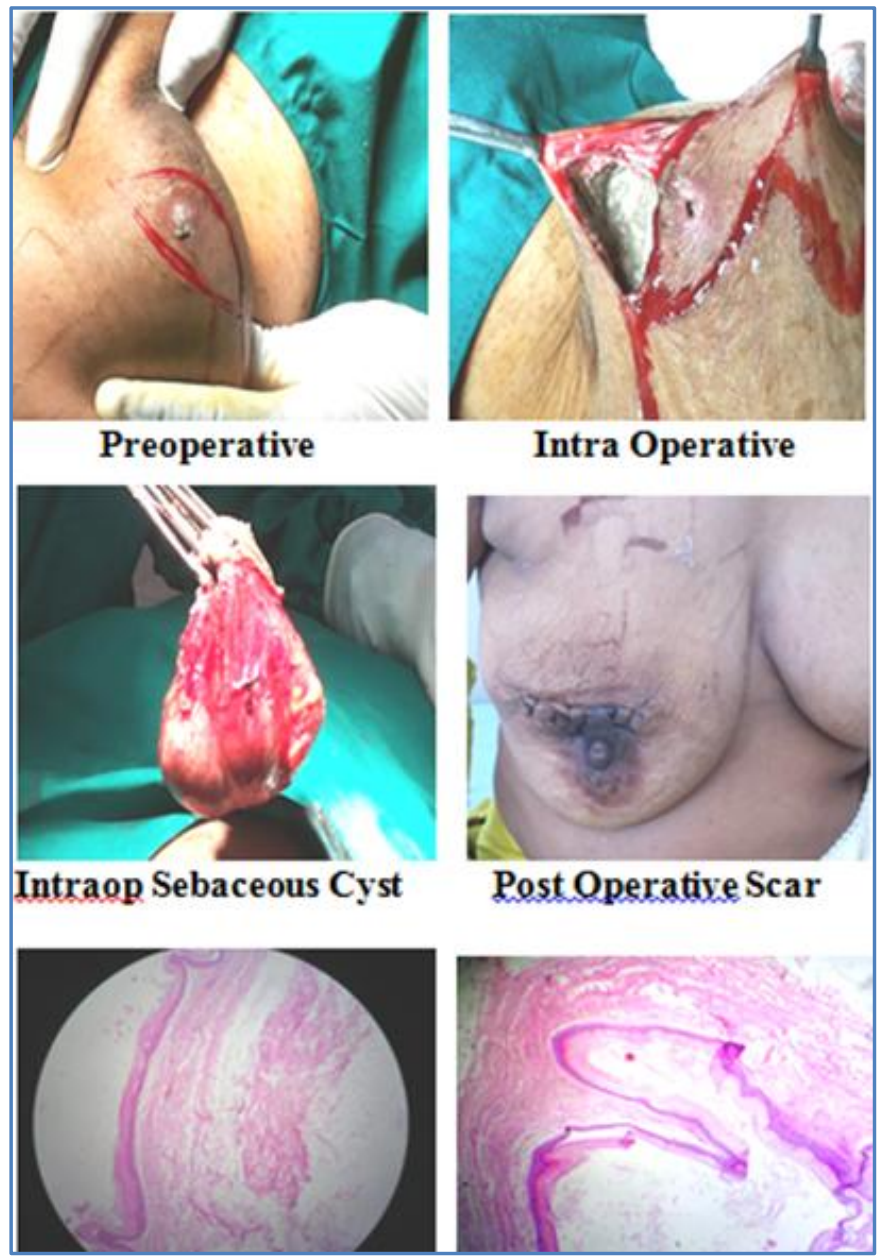

HPE report shows, cyst lined by stratified squamous epithelium with thickened fibro collagenous wall. Many proliferated blood vessels and congested large blood vessels and focal collection of chronic inflammatory cells inclusive of plasma cells and few epithelioid cells suggestive of Epidermal cyst with chronic inflammatory reaction.

\section{Complications:}

- Infection - inflammation

- Cyst rupture causing a foreign-body or granulomatous reaction, or abscess formation.

- Malignant transformation into a low-grade squamous cell carcinoma is extremely rare but has been reported. ${ }^{3}$

CONCLUSION: Surgical excision is the only treatment. Recurrence is common if incomplete excision.

\section{REFERENCES:}

1. Shaikh MH, Baviskar PK, Mahske AN. Sebaceous cyst in the breast: A Rare Presentation. Bombay Hospital Journal. (April 2011)Volume 53 No. 02. 


\section{CASE REPORT}

2. Kalli S, Freer PE, Rafferty EA. Lesions of the skin and superficial tissue at breast MR imaging. Radiographics. (2010) 30 (7): 1891-913.

3. Iglesias A, Arias M, Santiago P et al. Benign breast lesions that simulate malignancy: magnetic resonance imaging with radiologic-pathologic correlation. Curr Probl Diagn Radiol. (April 2007) 36 (2): 66-82.

\section{AUTHORS:}

1. Abhinash Hazarika

2. Geetha Avadhani

3. Nagesh K.

\section{PARTICULARS OF CONTRIBUTORS:}

1. Associate Professor, Department of Surgery, AIMS.

2. Head of Department, Department of Surgery, AIMS.

3. Post Graduate Student, Department of Surgery, AIMS.

\section{NAME ADDRESS EMAIL ID OF THE} CORRESPONDING AUTHOR:

Dr. Abhinash Hazarika,

Professor Quarters,

B-Block, No. 22,

AIMS, B. G. Nagar,

Nagamangala, Mandya.

Email: hazarikadrabinash@gmail.com

Date of Submission: 17/06/2014.

Date of Peer Review: 18/06/2014.

Date of Acceptance: 24/06/2014.

Date of Publishing: 07/07/2014. 